\title{
An assessment of borehole sealing performance in a salt environment
}

\author{
H. Akgün
}

\begin{abstract}
Design of plugs for abandonment of boreholes and shafts may be governed by the bond strength between the plug and host rock. This paper presents the results of push-out tests on cement grout plugs in salt. Two types of expandable cement grouts have been tested. The average interface shear strengths ranged from 2 to $12 \mathrm{MPa}$ (290 to 1740 psi). Peak shear stresses at failure, assuming an elastic stress distribution along the interface, were up to eight times higher. Standard deviations commonly reached $20 \%$. Dissolution along the interface was observed, and may have been enhanced by clay inclusions in the salt. This dissolution appears to have reduced bond strengths. Application of the results to the design of plugs for larger openings (for example, shafts, drifts, or boreholes) is discussed.
\end{abstract}

Key words Bond strength - Rock salt - Cement grout plug $\cdot$ Repository sealing

\section{Introduction}

Shafts and boreholes that penetrate aquitards can provide hydraulic connections between aquifers containing fresh water and formations containing saline waters. Contamination of high quality groundwater can result if such connections are not sealed adequately.

The growing recognition of the need to more adequately seal boreholes is well illustrated for example by the fact that the Transportation Research Board of the National

Received: 6 March 1996 • Accepted: 16 July 1996

H. Akgün

Department of Geological Engineering, Middle East Technical University, Ankara 06531, Turkey
Research Board of U.S. convened a Special Meeting on the Sealing of Geotechnical Exploratory Holes in conjunction with the 42nd Annual Highway Geology Symposium. The Transportation Research Board is also funding a major research project at the University of Massachusetts at Amherst on sealing exploratory holes (DeGroot and others 1991). The Environmental Protection Agency (USEPA) is also investigating borehole sealing (Smith and others 1990).

The subject of borehole sealing has received most attention in the petroleum industry, for fairly obvious reasons. Extensive design, and applications and practice manuals have been published (Smith 1976; Halliburton undated). Nevertheless, problems remain, especially with wells abandoned before rigorous abandonment practices became widely used (Suro 1992).

Seals or plugs in boreholes, shafts, or drifts connecting aquifers bearing unsaturated brine or water with salt mines, or, more generally, excavations in salt, may have the additional function of preventing the inflow of water or unsaturated brine into the openings. Such inflows could cause salt dissolution, with resultant collapses and deformations of the overburden that may be difficult to predict. Overburden deformations could further affect aquifers as well as the ground surface.

Penetrations (for example, boreholes, shafts, or drifts) of and near a high-level nuclear waste repository need to be plugged reliably to retard any radionuclide migration to the accessible environment. Axial loads on these plugs or seals due to brine, water, or gas pressures, or due to temperature changes induced subsequent to waste and plug emplacement lead to shear stresses at the plug/host rock contact (Akgün and Daemen 1991). These shear stresses may cause cracking and, thereby, increased permeability along a preferential path at the plug/rock interface. Under extreme conditions they could dislodge plugs. The bond between the plug and rock is a critical element for the design and performance of plugs. In order for the plugs to remain in place and to prevent increased hydraulic conductivities along plug/host rock interfaces, the plugs should have sufficient strength along the interface to resist axial loads and resultant shear stresses.

The objective of this paper is to record and evaluate the bond strength of expansive cement borehole plugs in salt cores as measured by push-out tests. The push-out test involves the use of a steel rod to dislodge a cement grout plug emplaced within the coaxial borehole of a hollow 


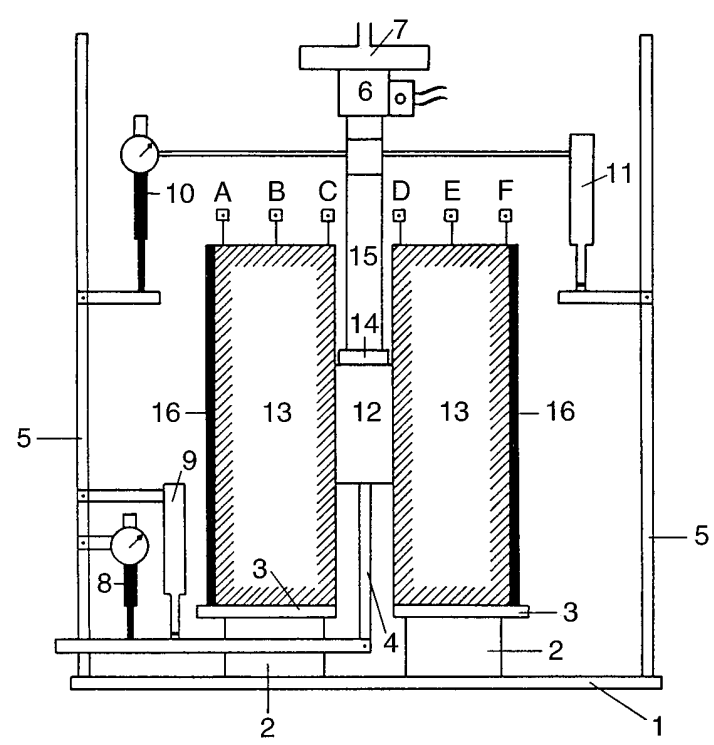

Fig. 1

Schematic drawing of push-out test setup (not to scale). 1 cylindrical steel plate, 2 circular plate with a slit, 3 square steel plate 4 L-shaped steel rod, 5 vertical steel rod, 6 load cell, 7 loading plate, 8, 10 dial gauge, 9, 11 LVDT, 12 cement grout plug, 13 rock salt sample, 14 steel disk, 15 axial rod, 16 steel pipe, A, B, C, D, E, F pins

rock cylinder (Fig. 1). Push-out test durations ranged from a few minutes to 2 days. Loads were incremented stepwise at intervals of minutes for short-term testing. Loads were kept constant for hours during longer term testing.

The salt specimens were taken from the Salado Formation in southeastern New Mexico. The Salado Formation consists of halite with regular but thin beds of anhydrite and polyhalite; clay seams are common at the base of the anhydrite-polyhalite seams.

\section{Push-out test experimental procedure}

The push-out specimens were prepared by coring $76.2 \mathrm{~mm}$ ( $3 \mathrm{in}$ ) radius, $127 \mathrm{~mm}$ ( $5 \mathrm{in}$ ) long salt cylinders from nearly cubic salt blocks having linear side lengths ranging from $0.5 \mathrm{~m}$ to $1 \mathrm{~m}$ (1.64-3.28 ft). A closed-end, diamond impregnated coring bit under high air pressure was used for coring the rock salt cylinders. The end surfaces of the cored rock cylinders were ground in order to obtain smooth and parallel end surfaces. Saturated brine was used as the grinding fluid. The $12.7-\mathrm{mm}$ (0.5-in) radius central hole of the push-out cylinders was drilled with a closed-end diamond impregnated bit under high air pressure. This was followed by placing a $13-\mathrm{mm}$ (0.525-in) radius rubber stopper into the central borehole at a level where a $25.4 \mathrm{~mm}$ ( 1 in) long centered cement plug was to be located. The cement slurry was poured onto this rubber stopper until a 25.4-mm (1-in) long cement plug was obtained. Cement grout mixing was performed according to American Petroleum Institute (API) specifications, API Standard No. RP-10B (1988). The cement plugs were cured under brine for 8 days prior to testing.

Two types of expandable cement grout formulations, provided by Dowell-Schlumberger, Tulsa, Oklahoma were prepared and tested: Self-Stress I cement grout and Saltbond II cement grout. Both of these cement grout formulations are Dowell-Schlumberger trademarks and their chemical compositions are not known or were allowed to be chemically tested by the authors. Self-Stress I grout slurry is prepared by mixing $659 \mathrm{~g}$ of Self-Stress I cement formulation with $493 \mathrm{~g}$ of $\mathrm{NaCl}$-saturated brine. Saltbond II grout slurry is prepared by mixing $1000 \mathrm{~g}$ of Class $\mathrm{H}$ cement, $450 \mathrm{~g}$ of NaCl-saturated brine, $64 \mathrm{~g}$ of D604 (a liquid additive) and $4.4 \mathrm{~g}$ of M45 (an anti-foam agent). Figures 1-3 show the push-out test setup. A steel rod

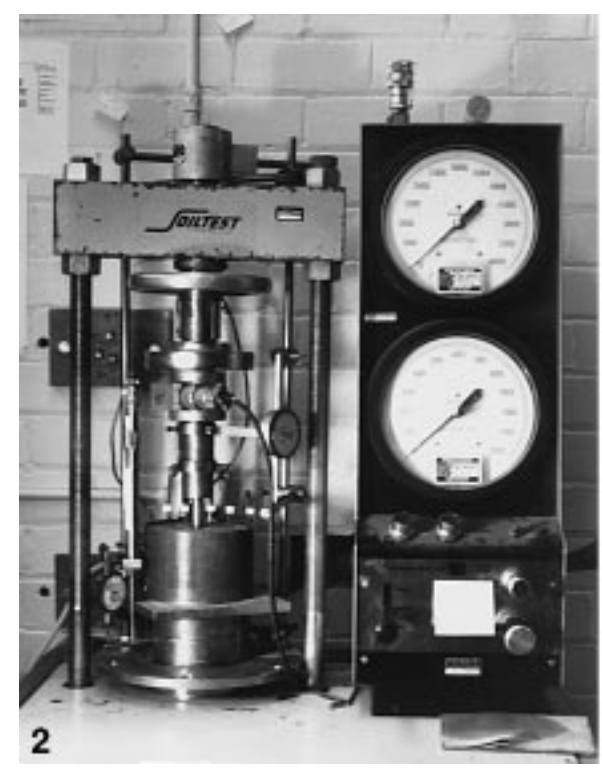

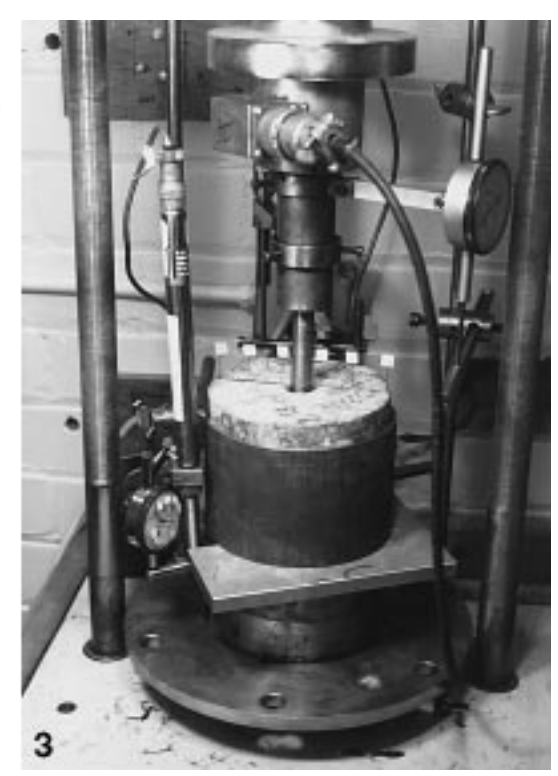

Fig. 2

A photograph of push-out test setup

Fig. 3

A close up view of push-out test setup 
transmits the load to the plug. The applied load is measured with a compression machine gauge and with a load cell. The top and bottom axial displacements of the borehole plug are measured with linear variable differential transformers (LVDTs) and with dial gauges. Two cylindrical jackets with horizontal arms are clamped onto the loading rod in order to mount the top LVDT and dial gauge for the top plug displacement measurements. An $\mathrm{L}$-shaped rod is screwed into the bottom of the cement plug. The horizontal arm of this rod supports the bottom LVDT and dial gauge for bottom plug displacement measurements. The bottom LVDT and dial gauge are clamped to fixed vertical reference rods.

Salt cylinders plugged with cement grout were tested for short- or long-term durations. In short-term testing, the sample was initially loaded to $4450 \mathrm{~N}$ (1000 lbf). The load was kept approximately constant and incremented by $4450 \mathrm{~N}$ (1000 lbf) every $5 \mathrm{~min}$ until the plug failed. The load and displacements were recorded every $30 \mathrm{~s}$. In long-term push-out testing, the procedure for short-term testing was repeated at constant loads of $4450 \mathrm{~N}$ (1000 lbf) and $8900 \mathrm{~N}$ (2000 lbf). Quasi-static loading was maintained at 13,350 N (3000 lbf) and 17,800 N (4000 lbf) for up to 2 days. The load, top and bottom plug displacements, and vertical upper rock surface displacements (vertical displacement of pins A through $\mathrm{F}$ as shown in Fig. 1) were recorded. The objective of long-term pushout testing was to determine whether the top cement grout plug displacement prior to failure was due to the flow (creep) of rock salt, or due to failure initiating at the upper end of the plug/rock salt interface and propagating downwards, or a combination of both.

\section{Shear stress distribution}

Many structures are mechanistically similar to an axially loaded borehole plug. Composite materials, reinforced concrete, piles, and rock bolts are examples. Akgün and Daemen (1991) have reviewed mechanical analyses of interaction configurations similar to push-out testing. The shear stress distribution induced by push-out loading along the cement plug/rock salt interface can be calculated as follows:

1. Assuming an average shear stress distribution:

$\tau_{\mathrm{av}}=\frac{\sigma_{\mathrm{po}} \mathrm{a}}{2 \mathrm{~L}}$

where: $\tau_{\mathrm{av}}$ is the average shear stress along the plug/rock salt interface, $\sigma_{\mathrm{po}}$ is the axial stress applied to the plug, a is the plug radius, and $\mathrm{L}$ is the plug length.

2. Assuming an exponential shear stress distribution (modifying the three-dimensional elastic solution by Akgün and Daemen (1991) for a one-dimensional stress field in the axial direction):

$\tau_{\mathrm{rz}, \mathrm{i}}=\frac{\sigma_{\mathrm{po}} \mathrm{a} \beta}{2} \frac{\cosh [\beta(\mathrm{L}-\mathrm{z})]}{\sinh (\beta \mathrm{L})}$, where: $\tau_{\mathrm{rz}, \mathrm{i}}$ is the exponential shear stress along the interface, $\beta^{2}$ is equal to $1 /\left[\mathrm{a}^{2}\left(\mathrm{E}_{\mathrm{p}} / \mathrm{E}_{\mathrm{R}}\right)\left(1+\nu_{\mathrm{R}}\right) \ln \left(\mathrm{r}_{\mathrm{m}} / \mathrm{a}\right), \mathrm{r}_{\mathrm{m}}\right.$ is the critical radius beyond which shear stresses in the rock are negligible and is equal to $\mathrm{a}+\left[2.1-0.38\left(\mathrm{E}_{\mathrm{p}} / \mathrm{E}_{\mathrm{R}}\right)\right] \mathrm{L}$, $\mathrm{z}$ is the distance from loaded end of plug, $\mathrm{E}_{\mathrm{P}} / \mathrm{E}_{\mathrm{R}}$ is the ratio of Young's moduli of plug and rock salt, and $\nu_{\mathrm{R}}$ is the Poisson's ratio of rock salt. Equation 2 is valid for a modulus ratio $\left(E_{P} / E_{R}\right)$ range of $0.233-10$.

It follows from Eq. 2 that the peak interface shear stresses occur at the loaded end of the plug/rock interface (such as, at $\mathrm{z}=0$ ). The peak shear stress $\left(\tau_{\mathrm{P}}\right)$ can thus be expressed as:

$\tau_{\mathrm{p}}=\frac{\sigma_{\mathrm{po}} \mathrm{a} \beta}{2 \tanh (\beta \mathrm{L})}$,

The equations for the exponential shear stress distributions given above require the use of material elastic properties. The average Young's modulus $\left(E_{R}\right)$ and Poisson's ratio $\left(\nu_{\mathrm{R}}\right)$ of the rock salt cylinders are taken to be $30 \mathrm{GPa}\left(4.35 \times 10^{6} \mathrm{psi}\right)$ and 0.35 , respectively (Hansen and others 1984). Self-Stress I cement and Saltbond II cement grout plugs exhibit average Young's moduli $\left(\mathrm{E}_{\mathrm{P}}\right)$ of $710 \mathrm{MPa}\left(1.03 \times 10^{5} \mathrm{psi}\right)$ and $7.1 \mathrm{GPa}\left(1.03 \times 10^{6} \mathrm{psi}\right)$, respectively. Both cement grout systems have an average Poisson's ratio $\left(\nu_{\mathrm{P}}\right)$ of 0.15 .

Figure 4 shows the exponential shear stress distribution per unit applied axial stress $\left(\tau_{\mathrm{rz}, \mathrm{i}} / \sigma_{\mathrm{po}}\right)$ along an axially

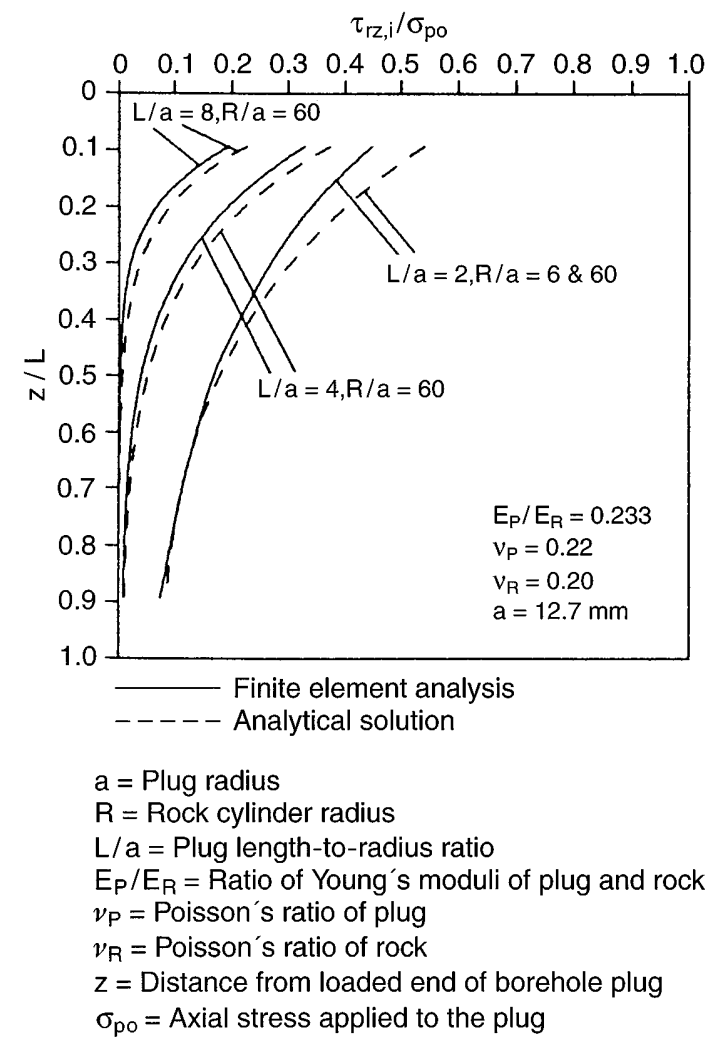

Fig. 4

Exponential shear stress distribution per unit axial $\operatorname{stress}\left(\tau_{\mathrm{rz}, \mathrm{i}} / \sigma_{\mathrm{po}}\right)$ along an axially loaded borehole plug as obtained analytically and numerically 


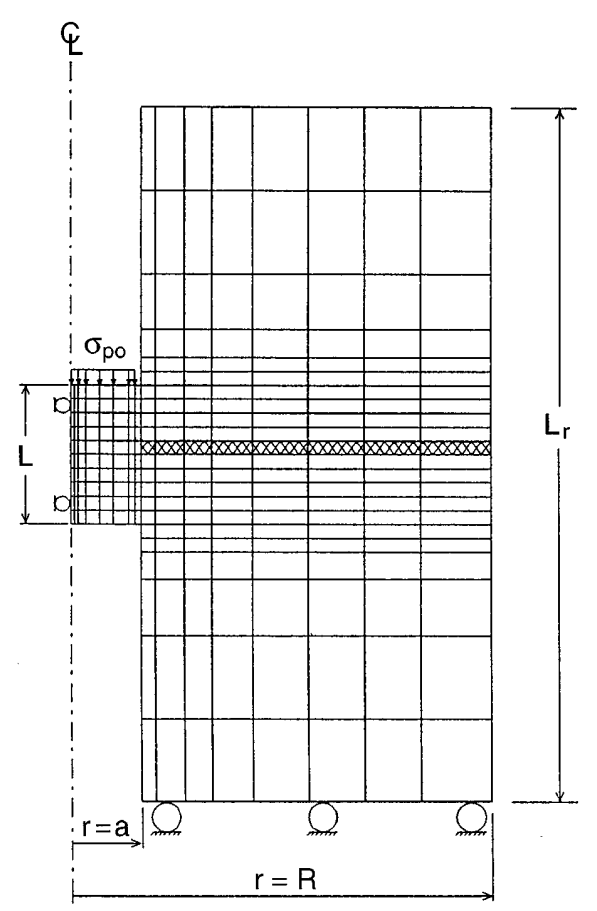

$25.4 \mathrm{~mm}$

Fig. 5

Finite element mesh and boundary conditions for a push-out specimen. $\sigma_{\mathrm{po}}=$ axial stress applied to the plug, $a=$ plug radius, $L=$ plug length, and, $R=$ rock cylinder radius

loaded borehole plug as obtained through Eq. 2 and through finite element analysis. Figure 5 shows a finite element mesh for a push-out specimen. An axisymmetric finite element program, PLANE-2DFE, is used to determine the stress distribution within an axially loaded push-out specimen. Desai (1979) gives the finite element formulation for the four-node isoparametric axisymmetric elements used in this analysis. The finite element analysis simulates a push-out test on an elastic material with an applied axial stress $\left(\sigma_{\mathrm{po}}\right)$ of $1.0 \mathrm{MPa}$ (145 psi). The mesh consists of 256 elements and 295 nodal points, and represents a laboratory size push-out specimen with a plug radius of $12.7 \mathrm{~mm}$ ( $0.5 \mathrm{in})$, rock cylinder outsideto-inside radius ratio of 6 and plug length-to-radius ratio of 2 . The hatched region in Fig. 5 shows the rock section in which the shear stress distribution within the rock section was studied in detail in order to find a formulation for the critical radius beyond which the shear stresses in rock are negligible.

The results presented in Fig. 4 are given as a function of plug length-to-radius ratio (L/a) and rock cylinder outside-to-inside radius ratio (R/a). The peak shear stress increases with decreasing plug length. Rock cylinder outside-to-inside radius ratio has negligible influence on the peak shear stress.

\section{Push-out test results and discussion}

Cylinders plugged with Self-Stress I cement

Self-Stress I cement push-out samples had a $76.2 \mathrm{~mm}$ ( 3 in) outside radius, $12.7-\mathrm{mm}(0.5$-in) inside radius and cylinder lengths of $127 \mathrm{~mm}$ (5 in). The nearly centered solid cement grout plugs were cast in place and cured under brine for 8 days. The cement grout plugs had radii of $12.7 \mathrm{~mm}(0.5 \mathrm{in})$ and lengths of about $25.4 \mathrm{~mm}(1 \mathrm{in})$ (plug length-to-radius ratios of approximately 2 ). Specimens plugged with Self-Stress I cement grout were tested for a short-term duration. Table 1 summarizes the mean axial strength, mean bond strength, and mean peak shear stress at failure for the six specimens tested. The axial strength and bond strength are defined as the applied axial stress at failure $\left(\sigma_{\mathrm{po}}\right)$ and the average shear stress at failure $\left(\tau_{\mathrm{av}}\right)$, respectively. The mean bond strengths of the Self-Stress I cement grout push-out plugs were $2.2 \mathrm{MPa}$ (319 psi), with a standard deviation of $0.5 \mathrm{MPa}$ (73 psi). The bond strength ranged from 1.2 $\mathrm{MPa}$ (174 psi) to $2.6 \mathrm{MPa}$ (377 psi). The mean peak shear stress at failure was about eight times higher than the mean bond strength.

\section{Cylinders plugged with Saltbond II cement}

Thirty four push-out tests were performed on salt cylinders plugged with Saltbond II cement grouts: 26 shortterm and 8 long-term tests. The plugs were cured under brine for 8 days. The push-out cylinders had the same geometries as those reported in the previous section. Table 1 presents the mean axial strength, mean bond strength, and mean peak shear stress at failure for the 34 specimens tested. The mean peak shear stress at failure was more than five times the mean bond strength. Saltbond II cement grout plug top displacements were higher than the plug bottom displacements prior to failure. The plugs contracted by up to $2 \mathrm{~mm}(0.08 \mathrm{in})(8 \%$ of the plug lengths) at failure. The axial rock displacements at various pin locations (Fig. 1) ranged from 0 to $3.4 \mathrm{~mm}$ $(0.134 \mathrm{in})$ at a constant axial load of $13,350 \mathrm{~N}$ (3000 lbf). At $17,800 \mathrm{~N}(4000 \mathrm{lbf})$ they decreased to a range of $0-$ $0.811 \mathrm{~mm}$ ( $0.032 \mathrm{in})$. The most likely reason for the decreased axial rock displacements with increased constant load is believed to be the initiation of plug slippage. Figure 6 presents the results of a representative long-term push-out test which was conducted for 2 days. The applied axial stress, top and bottom axial plug displacements, and ranges of axial rock displacements at various pin locations are plotted as a function of time. The locations where the rock displacements are measured are shown in Fig. 1. On the average, the axial rock displacements at various pin locations were about $71 \%$ of the top plug displacements prior to failure. The difference in the slopes of the top and bottom plug displacements and axial rock displacements indicates simultaneous plug compression and rock flow. Failure of the plug is accompanied by a decrease or partial recovery of the axial rock 
Table 1

Mean strength parameters for the push-out cylinders \pm one standard deviation. The number of samples tested is given in parentheses

\begin{tabular}{llll}
\hline Salt & Mean & Mean bond & Mean peak \\
cylinder & axial & strength & shear \\
& strength & $(\mathrm{MPa})$ & stress at \\
& $(\mathrm{MPa})$ & & failure \\
& & $(\mathrm{MPa})$
\end{tabular}

\section{Plugged}

with Self-

Stress I

cement (6)

$8.7 \pm 3.8$

$2.2 \pm 0.5$

$18.1 \pm 7.4$

Plugged

with

Saltbond II

cement (34)

$29.2 \pm 7.8$

$6.1 \pm 2.1$

$31.7 \pm 8.8$

With rock

bridge (3)

$83.5 \pm 3.7$

$10.1 \pm 1.0$

$26.6 \pm 1.2$

displacements at various pin locations (such as, the slope of the axial rock displacement decreases towards initiation of bond separation, as shown in Fig. 6). The bond separation leads to the relaxation of the rock salt cylinder.

\section{Dissolution of the Saltbond II cylinders}

Dissolution of the rock salt along the cement grout/salt interface is a major concern in borehole cement grouting, as well as in borehole sealing (George and Faul 1985). Almost $50 \%$ of the push-out cylinders plugged with Saltbond II cement grout exhibited dissolution along the top of the borehole and along the cement grout/borehole interface. Samples showing no dissolution generally exhibited high axial stresses at failure, and failed through the grout rather than by bond separation along the interface, indicative of a good bond. Those showing dissolution generally failed at lower loads and sheared along the cement grout/salt interfaces, indicating poor bonding. Figure 7 shows a cut section of specimen S5-5-1 after failure in the push-out test at an axial stress $\left(\sigma_{\mathrm{po}}\right)$ of $45 \mathrm{MPa}$ (6525 psi). The thick cement residue on the borehole walls above the cement plug (towards the left of the cement plug in Fig. 7) and the absence of dissolution indicates good bonding and most probably a high axial strength. Figure 8 shows a close-up view of sample S5-5-1 cut along the axis. Figure 9 shows a cut section of specimen S5-4-5 after failure at an axial stress of $25 \mathrm{MPa}$ (3635 psi). The absence of cement residue on the borehole walls above the cement plug (towards the left of the cement plug in Fig. 9) and the presence of dissolution along the interface indicates poor bonding and most probably a reduced axial strength. Qualitative results from X-ray diffraction showed that the rock salt contained clay. The clay minerals showed some expansion in ethylene glycol and could have been of the montmorillonite group. The observation that clays expand in high
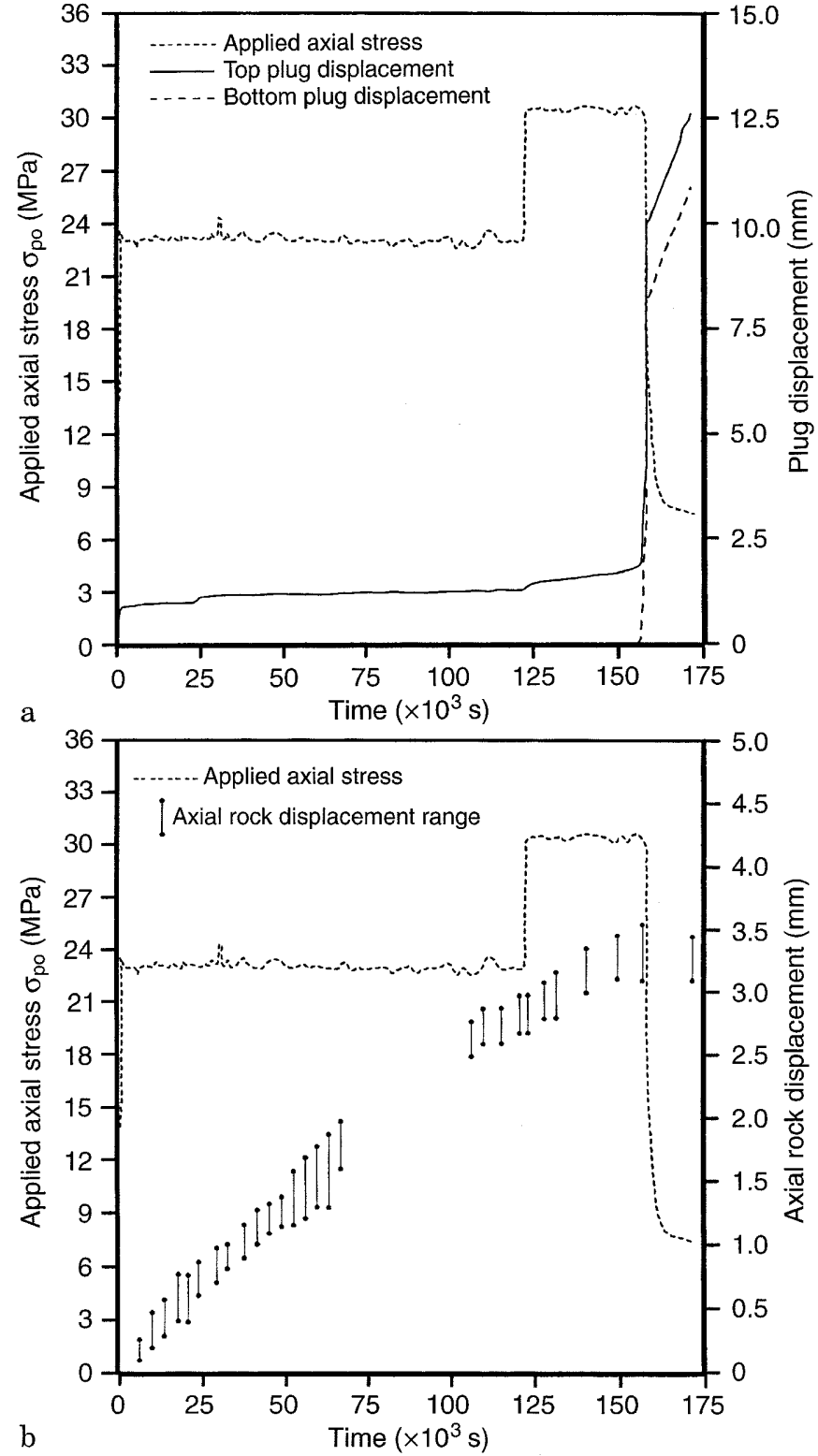

Fig. 6a,b

The applied axial stress, a top and bottom cement grout plug axial displacements, and $\mathbf{b}$ ranges of axial rock displacements measured at various pin locations vs. time for the long-term push-out test specimen S5-3-5. Fig. 1 gives the pin locations

humidity or brine, which can lead to dissolution (Wakeley and others 1981), was confirmed by leaving crushed rock salt samples in brine. Clay minerals expanded and dissolved, which most probably led to reduced strength.

\section{Push-out tests on rock bridges}

Three push-out tests were performed on rock bridge specimens. The rock bridge samples were prepared by coring a top and a bottom coaxial hole in a salt cylinder, thus leaving a centered rock salt bridge in place. Experiments on rock salt bridges provided a strength reference against which cement grout/salt interface strengths have 


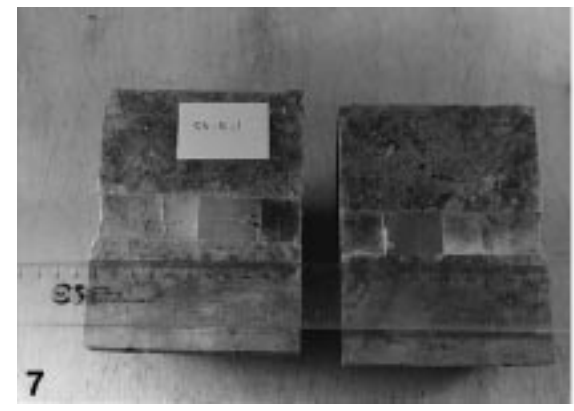

Fig. 7

Cut section of push-out specimen S5-5-1

Fig. 8

Close up view of push-out specimen S5-5-1

Fig. 9

Cut section of push-out specimen S5-4-5

been compared. The push-out cylinders with rock bridges had similar geometries to the plugged samples except for rock bridge length-to-radius ratios of 4 . Table 1 summarizes the mean axial strength, mean bond strength, and mean peak shear stress at failure. The Self-Stress I cement grout push-out samples had a mean bond strength $22 \%$ of that of samples with rock bridges; the Saltbond II cement plugs had a higher mean bond strength, $60 \%$ of the rock bridge samples. Attaining $60 \%$ of the mean bond strength of the rock bridge samples most likely indicates good mechanical and (at least short-term) chemical compatibility, resulting in better bonding and higher strength for Saltbond II cement grout push-out samples.

\section{Design considerations}

Bond strength is an important design parameter for plugs. Relatively little experimental data is available for the design of cementitious grout plugs in salt. Moreover, the results are also difficult to integrate into relatively simple design criteria, because of the wide range of conditions and test configurations under which they have been obtained. The results presented in this paper considerably expand the available experimental data base, and as such can assist in guiding the design of cement grout plugs in rock salt.

The main limitations of the test program as completed are the narrow range of plug geometries (borehole radii and plug lengths), the absence of confining pressure, and the relatively short duration of the tests. Because of the narrow range of plug geometries, the axial strength cannot be extrapolated to larger or longer plugs. Akgün and Daemen (1991) studied the effects of borehole size and plug length on the axial strength of cement plugs emplaced in welded tuff cores. They used inside borehole radii of $6.35 \mathrm{~mm}(0.25 \mathrm{in}), 12.7 \mathrm{~mm}$ (0.5 in), $25.4 \mathrm{~mm}$ (1 in) and $50.8 \mathrm{~mm}$ ( $2 \mathrm{in}$ ); and plug length-to-radius ratios of 2, 4 , and 8 . Figures 10 and 11 are from their study. Fig-

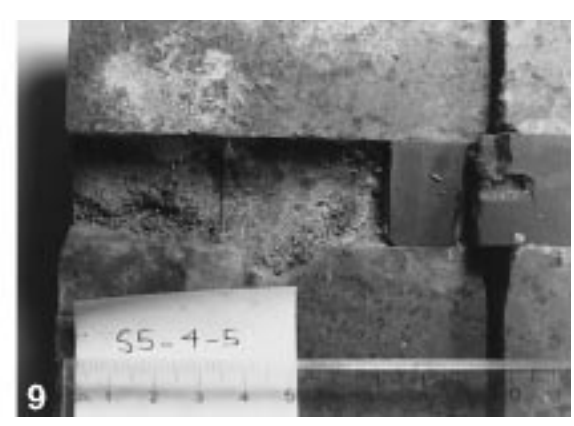

ure 10 presents a best fit of the upper, mean, and lower bounds of the normalized axial stresses $\left(\sigma_{\mathrm{z}, \mathrm{f}}^{\mathrm{p}}\right)$ at failure vs. plug radii for plugs with length-to-radius ratios of 2 . The axial stress is normalized to cylinders with a common outside-to-inside radius ratio of infinity. The curves obey a well-defined power law (with exponents in the neighborhood of 0.5 ) and show a decrease in axial strength with increased plug radius. Figure 11 shows the normalized axial strength $\left(\sigma_{\mathrm{z}, \mathrm{f}}^{\mathrm{p}}\right)$ of a $12.7 \mathrm{~mm}(0.5 \mathrm{in})$ radius plug as a function of plug length-to-radius ratio. The axial strength increases with increasing plug length. The analytical study performed by Akgün and Daemen (1991) showed that the axial strength did not increase beyond a plug length-to-radius ratio of 10 .

Akgün and Daemen (1991) analytically studied the influence of confining pressure on the axial strength of push-out cylinders. The radial (contact) stress at the plug/rock contact increased with increasing confining pressure, leading to increased axial strength.

The results of the push-out tests in salt cores represent lower bounds of axial strengths due to the absence of confining pressure and due to the use of relatively short plugs. The advantage of a longer plug is also realized at slip (at post failure). When slip occurs, the portion of the plug which fails still transfers some load to the rock through residual shear strength, down to some point

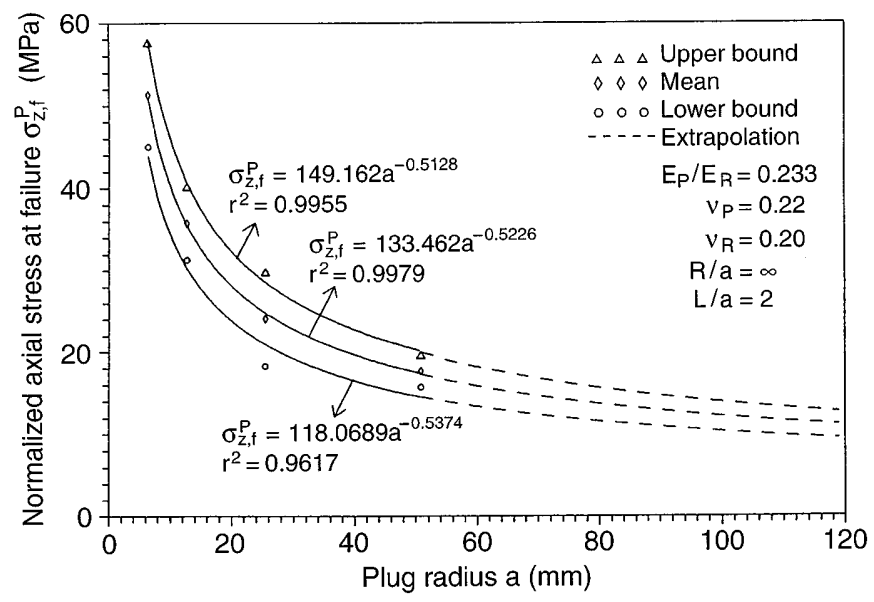

Fig. 10

Normalized axial strength $\left(\sigma_{\mathrm{z}, \mathrm{f}}^{\mathrm{p}}\right)$ for welded tuff push-out cylinders as a function of plug radius. $r^{2}=$ coefficient of determination. Equations 1 and 2 give the definition of all variables. (Note: NRC reports do not have copyright!) 


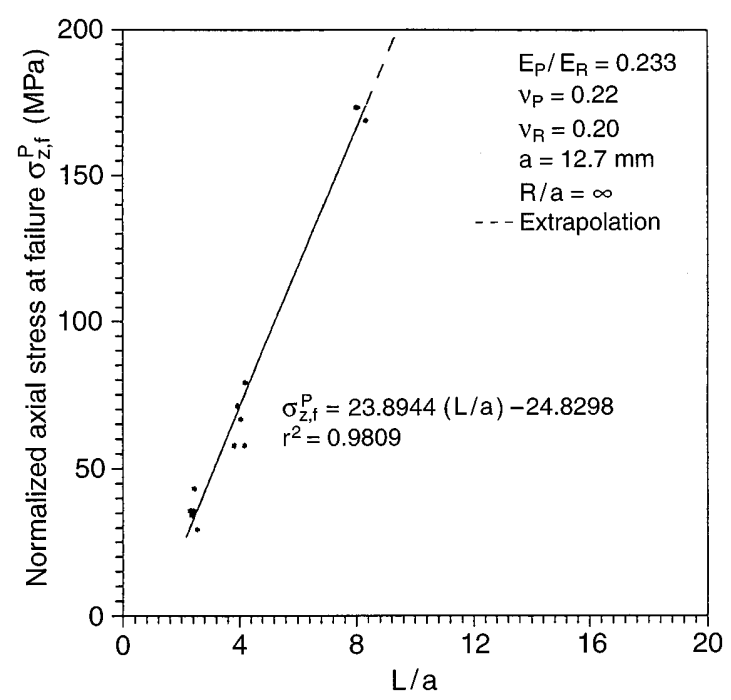

Fig. 11

Normalized axial strength $\left(\sigma_{\mathrm{z}, \mathrm{f}}^{\mathrm{p}}\right)$ for welded tuff push-out cylinders as a function of plug length-to-radius ratio (L/a). Equations 1 and 2 give the definition of all variables.

along the interface (Hollingshead 1971). The intact portion of the plug/rock interface, below this particular point, transfers the remainder of the load by an elastic, redistributed exponential shear stress, with a reduced peak shear stress. A longer plug has a longer intact portion and higher strength upon failure.

The design of plugs in salt must also consider the effect of creep closure onto the cement grout plug. Creep closure will increase the effectiveness of the plugs by increasing the radial (contact) stress at the interface (Nelson and Kelsall 1984). Increased contact stress will lead to increased strength. In summary, an elastic analysis in salt is conservative, as it does not take into account progressive failure (which leads to reduced peak shear stresses) and does not consider rock creep closure onto the plug which increases strength. Conversely, it may be desirable to use an elastic analysis and to remain on the conservative side, especially when plug design is for permanent abandonment.

The results of this study show that shorter plugs give higher bond strengths. The peak shear stress at failure and axial strength increase with increasing plug length. The mean peak shear stress at failure is up to eight times greater than the mean bond strength. Particularly for different plug geometries, strength comparisons must be based on a rigorous definition of failure stress distributions. The results of the finite element analysis shows that the peak shear stress, calculated from Eq. 2, reflects a more realistic interface shear stress. The results of the finite element analysis also showed that the average shear strength should only be used for rigid borehole plugs, such as when the Young's modulus of the plug is much higher than that of the rock. As the Young's modulus of the plug in this study is lower than that of the rock, an appropriate strength comparison must be based on either the peak shear stress at failure or the axial strength. For the general design case, it may be desirable to base a conservative design on limiting the peak interface shear stress.

The author recommend that the design of permanent abandonment plugs be based on limiting the peak interface shear stress, as calculated elastically from Eq. 3, to a value well below the peak shear strength. Some guidance about peak shear strength is given in the last column of Table 1. These peak shear strengths need to be derated for size effects. Based on related experiments in tuff, it is believed that a conservative design will result if the strengths in Table 1 are divided by a factor of 18 for full size (for example, $6 \mathrm{~m}$ (20 ft) diameter) shafts. Such a design should also result in stress levels well below those at which creep is likely to be induced. For situations where high axial loads preclude meeting these design criteria, a more detailed analysis is recommended.

Based on detailed numerical analyses of the mechanical and hydrological performance of seals (Akgün and Daemen 1986; Akgün and Daemen 1991; Akgün 1996; Greer and Daemen 1991), the author recommend that permanent abandonment plugs be designed with a length-to-radius ratio of eight. This somewhat conservative length criterion will preclude the development of significant, potentially detrimental tensile stresses in the host rock and in the plug. Assuming that the host rock is reasonably impermeable, e.g., has a hydraulic conductivity not exceeding that of the plug by two orders of magnitude, this length criterion will provide a balanced plug-rock seal system.

\section{Recommendations for further research}

It would be desirable to perform tests on plugs installed in confined cylinders, or pressurized cylinders, in order to determine the effect of normal stresses across the interface on the bond strength. Experiments on larger diameter plugs would be helpful in identifying size effects on bond strength, and in particular to evaluate the validity of a power law extrapolation for cement grout bond strength in salt. It would be desirable to conduct pushout tests over much longer durations, e.g., durations over which salt creep and cement grout creep might significantly affect bonding. Such experiments would also provide an opportunity to evaluate creep predictions under highly nonuniform stress and strain distributions, evaluations rarely given in the extensive literature on salt creep. The wide range of measured strengths follows in part from grouping results of tests conducted under somewhat different conditions, for example, with regard to test duration. The results also are notably affected by differences in dissolution along the interface. It may be possible to reduce the variability by narrowing the test specifications, especially with regard to geological and hydrogeological 
conditions (for example, host rock and aquitard composition and their nonuniformity), plug mixing, and test procedures. Alternatively, an investigation of mineralogy and brine effects on dissolution and its effect on bonding may result in identifying causes of strength reduction.

\section{Summary and conclusions}

This paper describes the results of push-out tests performed on cement grout plugs emplaced in salt cores. Two types of expansive cement grouts have been tested. Test durations varied from minutes to 2 days. Average bond strengths, assuming average shear stress distributions, ranged from 2 to $12 \mathrm{MPa}$ (290-1740 psi). Peak shear stresses at failure, calculated by assuming an elastic exponential shear stress distribution along the interface, were up to eight times higher. Standard deviations were commonly $20 \%$ or more. It is postulated that dissolution along the interface may have been induced by the dissolving of clay inclusions within the salt. Visible dissolution appears to be related to reduced axial and bond strengths. An elastic analysis in salt leads to conservative plug design, because it does not invoke the observed considerable residual strength along "failed" plug lengths. The salt cylinders plugged with Self-Stress I cement grouts gave a mean bond strength of $2.2 \mathrm{MPa}$ (319 psi), $22 \%$ of that measured on samples with rock bridges. The Saltbond II cement grout push-out samples gave a mean bond strength of $6.1 \mathrm{MPa}$ ( $885 \mathrm{psi}$ ), $60 \%$ of that of samples with rock bridges. Hence, bonding between rock salt and Saltbond II cement grout plugs is better than for Self-Stress I cement grout.

Acknowledgements The author wishes to thank Professor Jaak J. K. Daemen, Acting Dean, Mackay School of Mines, University of Nevada - Reno for his contributions to this paper. U.S. Nuclear Regulatory Commission's permission to publish this paper is gratefully acknowledged.

\section{References}

AKgün H and Daemen JJK (1986) Size influence on the sealing performance of cementitious borehole plugs. Washington, D.C.: U.S. Nuclear Regulatory Commission Technical Report NUREG/CR-4738

AKGÜN H and DAEMEN JJK (1991) Bond strength of cementitious borehole plugs in welded tuff. Washington D.C.: U.S. Nuclear Regulatory Commission Technical Report NUREG/ CR-4295

AKGÜN H (1996) Strength parameters of cement borehole seals in rock. In: Fuenkajorn K and Daemen JJK (Eds), Sealing of boreholes and underground excavations in rock. London: Chapman and Hall. pp 28-39

American Petroleum Institute (1988) Specifications for materials and testing for well cements, API Specification 10 (Spec 10). Fourth edition. Washington, D.C.: American Petroleum Institute, $103 \mathrm{pp}$

DeGroot DJ, Lutenegger AJ, and Mirza C (1991) Sealing geotechnical exploratory holes to protect the subsurface environment. Geotech News 9:40-42

DESAI CS (1979) Elementary finite element method. Englewood Cliffs, New Jersey: Prentice-Hall, Inc. 434 pp

George C and Faul R (1985) Cementing techniques for solution mining wells and salt storage domes: the state of the art. In: Schlitt WJ (Ed), Salts and brines. New York, New York: Society of Mining Engineers of AIME. pp 11-23

GrEeR WB and DAEMEN JJK (1991) Analyses and field tests of the hydraulic performance of cement grout borehole seals. Washington D.C.: U.S. Nuclear Regulatory Commission Technical Report NUREG/CR-5684

Halliburton (undated) Cement plug studies. Duncan, Oklahoma: Halliburton Services, $330 \mathrm{pp}$ (not paginated)

Hansen FD, Kirby DM and SEnseny PE (1984) Elasticity and strength of ten natural rock salts. In: Hardy, Jr. HR and Langer M (Eds), Mechanical behavior of salt I. Rotterdam, The Netherlands: A. A. Balkema. pp 71-83

Hollingshead GW (1971) Stress distributions in rock anchors. Can Geotech J 8:588-592

Nelson JW and Kelsall PC (1984) Prediction of long-term creep closure in salt. In: Dowding CH and Singh MM (Eds), Rock mechanics in productivity and protection. New York, New York: Society of Mining Engineers of AIME. pp 11151125

Smith DK (1976) Cementing. New York, New York: Society of Petroleum Engineers of AIME. $184 \mathrm{pp}$

Smith MD, Perry RL, Stewart GF, Holloway WA, and Jones FR (1990) A feasibility study of the effectiveness of drilling mud as a plugging agent in abandoned wells. Stillwater, Oklahoma: USEPA Report NTIS Order Number PB 90227232/AS

Suro R (1992) The toxic legacy of dead oil wells - improperly plugged sites are polluting water tables and causing surface explosions. San Francisco, California: San Francisco Sunday Examiner \& Chronicle. May 31, 1992. Sunday Punch. p 2

WAKeley LD, Roy DM and Grutzeck MW (1981) Experimental studies of seal materials for potential use in a Los Medanos-type bedded salt repository. Columbus, Ohio: Office of Nuclear Waste Isolation, Battelle Memorial Institute Technical Report ONWI-325 